\title{
ABORDAGEM DO LUGAR NOS LIVROS DIDÁTICOS DE GEOGRAFIA UTILIZADOS DO ENSINO MÉDIO EM ESCOLAS PUBLICAS DE FEIRA DE SANTANA
}

\author{
$\underline{\text { Muana Silva de Almeida }}{ }^{1}$; Célia Regina Batista dos Santos $^{2}$ \\ 1. Bolsista PIBIC/CNPq, Graduando em Licenciatura em Geografia, Universidade Estadual de Feira de \\ Santana, e-mail: muana_muk@hotmail.com \\ 2. Orientador, Departamento de Educação, Universidade Estadual de Feira de Santana, e-mail: \\ celia_regina2006@hotmail.com
}

PALAVRAS-CHAVE: Geografia Escolar; Livro Didático, Lugar.

\section{INTRODUÇÃO}

Este trabalho teve como proposta analisar a concepção e forma de abordagem do Lugar nos livros didáticos de Geografia, particularmente no ensino médio. De acordo com Callai (2006), na literatura geográfica, o lugar está presente de diversas formas. No seu ponto de vista, estudá-lo é fundamental, pois ao mesmo tempo em que o mundo é global, as coisas da vida, as relações sociais se concretizam nos lugares específicos. E como tal, a compreensão da realidade do mundo atual se dá a partir dos novos significados que assumem a dimensão do espaço local. Mas quando se volta para a realidade dos livros didáticos utilizados nas escolas da rede pública de Feira de Santana, percebe-se que o espaço local geralmente não é abordado, por serem, em sua maioria, produzidos por escritores da região sudeste e sul do Brasil e por raramente conhecerem a realidade particular de cada lugar.

Apoiados nas ideias anteriormente ressaltadas e na pesquisa maior, a análise foi realizada com livros didáticos do $2^{\circ}$ ano do ensino médio, pois se entende que os conteúdos desse período são trabalhados de forma mais aprofundada. As questões que nortearam nossa análise foram: como o conceito de lugar é tratado nos livros didáticos do ensino médio das escolas pulicas da educação básica de ensino de Feira de Santana? As atividades sugeridas proporcionam aos alunos reflexões e questionamentos sobre o seu lugar de vivência? De que forma os conteúdos abordados e as atividades sugeridas nos livros didáticos analisados podem servir de subsídios na elaboração de materiais didáticos/pedagógicos sobre o lugar?

Para responder a essas perguntas estabelecemos algumas metas: investigamos os conteúdos abordados e suas relações/adequações aos conceitos de lugar estudados no grupo de pesquisa; identificamos as atividades propostas nos livros didáticos com o conteúdo sobre lugar e se as mesmas proporcionavam aos alunos reflexões sobre o seu espaço de vivência (o imediato concreto: bairro, cidade, município); avaliamos como as informações coletadas poderiam ser utilizadas como fonte de dados para os materiais didáticos sobre Feira de Santana.

\section{MATERIAL E MÉTODOS OU METODOLOGIA (ou equivalente)}

O lócus dessa pesquisa são os colégios de educação básica de Feira de Santana, onde o Grupo de Pesquisa Lugar/Feira de Santana tem uma relação colaborativa, tendo como meio de pesquisa os livros didáticos do $2^{\circ}$ ano do ensino médio desses. Essa escolha não foi aleatória, mas intencional, pois os livros desse ano trabalhão com o a geografia humana onde é trabalhado a sociedade como todo e assim os conceitos de rural e urbano, espaço e território em conjunto com o conceito de Lugar. A partir daí foi feita uma análise para saber de que forma o conceito de lugar é tratado nos livros, e qual a relação que eles sugerem que os professores façam dos conteúdos tratado nos livros com a cidade de vivencia dos alunos. O processo de elaboração dessa pesquisa seguiu algumas etapas não excludentes: a primeira etapa foi a elaboração da discussão teórica a 
partir dos conceitos-chave que norteiam a pesquisa, tendo como fontes dissertações, livros, artigos e monografias voltados para o ensino de geografia, material didático, o estudo do lugar, livro didático, a cidade de Feira de Santana entre outras; a segunda etapa foi a escolha dos livros didáticos a serem trabalhados. Esses tem o mesmo ano de publicação, são da mesma série, mas com autores diferentes: Geografia em Redes de Edilson Adão e Laercio Furquim Jr; Conexões Estudos de Geografia Geral e do Brasil de Lygia Terra, Regina Araújo e Raul Borges Guimarães; e Geografia Contextos e Redes de Angela Corrêa da Silva Nelson Bacic Olic e Ruy Lozano. Para a realização da análise, elaboramos uma ficha de avaliação e a apreciação dos livros a partir dos seguintes critérios: número de páginas dedicadas ao conteúdo; linhas de abordagem do conceito de lugar; salienta a função social do estudo do lugar; palavraschave e conceitos abordados no livro para realização da análise; imagens relacionadas ao lugar; tratamento do conceito de lugar ao longo do livro; atividades propostas; articulação com o lugar de vivencia e com os conhecimentos dos alunos; exploração do significado do lugar para os alunos. Por fim, foi realizada a organização, tabulação e análise dos dados encontrados no decorrer de todo o processo de investigação, confrontando com o referencial teórico.

\section{RESULTADOS E/OU DISCUSSÃO (ou Análise e discussão dos resultados)}

Os processos de globalização/regionalização atuais, de virtualização das relações humanas e sociais e de desterritorialização, produzem novas geografias no e para 0 mundo, e tem diretas implicações nos espaços sócio-espaciais, sejam eles no âmbito da cultura, da educação, da economia, da política e de outros campos da atividade humana.

Diante desse contexto, de acordo com Thisen (2011), percebe-se um redesenho das relações geopolíticas nos espaços local, regional e mundial, com uma reformulação das expectativas populacionais que demanda a implementação de políticas educacionais e, por conta disso, a necessidade, também, de um redesenho na organização dos tempos e dos espaços da escola. Nas palavras do referido autor:

Esse movimento social e educativo mais amplo passa a exigir que educadores e gestores, promovam modificações mais substanciais nas propostas curriculares, nas formas de organização do trabalho docente e nos processos metodológicos que fazem as transposições didáticopedagógicas das diferentes áreas de conhecimento científico para a educação escolar (THISEN, 2011, p. 02).

Isso ocorre de forma particular no campo da geografia, onde a realidade e as expectativas não são opostas. Onde de um lado, educadores e pesquisadores se esforçam para articular o conhecimento geográfico acadêmico e científico ao conhecimento geográfico escolar, como forma de auxiliar na formação dos estudantes, mas de outro, os resultados apresentados pelas escolas evidenciam as falhas existentes na educação. Ao perceber isso se faz necessário que utilizar a geografia, através do certo domínio e responsabilidade que possui devido a amplitude de conhecimentos fundamentais para a formação do indivíduo, auxiliando assim nas práticas escolares. Sobre isso Thisen (2011, p. 10) diz que:

Seu domínio (campo de conhecimento) e responsabilidade, um conjunto de saberes absolutamente fundamentais para a formação das crianças, dos adolescentes e dos jovens, por isso, as práticas escolares devem efetivar-se de forma a possibilitar que esses saberes sejam materializados com o máximo de extensão (universo conceitual e atitudinal) e profundidade (tratamento científico).

Entretanto, embora concordemos com o autor acima e tenhamos consciência sobre a relevância do conhecimento geográfico, Junior (2009, p. 09) faz uma observação importante sobre a tradição e a forma como é trabalhada nas escolas quando ressalta que, infelizmente, a tradição do ensino de geografia - particularmente no Ensino Fundamental e Médio, ainda indica um forte viés descritivo, principalmente do 
meio físico. Ressalta, ainda, que na medida em que há um discurso e prática da observação e descrição dos lugares, retira-se a conotação política da prática pedagógica e da relação ensinoaprendizagem. Em outras palavras, o autor destaca que isso significa uma despolitização das relações sociais que permeiam a sociedade e como esta se organiza para manter sua existência.

A Geografia que defendemos aqui está longe dessa inspiração positivista/ mecanicista, abstrata e que se norteia pela neutralidade política: ela é comprometida com a diversidade e complexidade dos espaços onde os homens pensam e dão forma aos seus objetivos pela cultura, pelo trabalho, pela história e pelas relações sociais que estabelecem entre si e com o mundo.

Concordamos com Thisen (2011) quando o mesmo afirma que a Geografia escolar (e aqui situo os conteúdos do livro didático e a forma como são abordados) deve se colocar como uma área de conhecimento comprometida socialmente que auxilia na produção da condição humana e na construção consciente dos espaços, sejam eles naturais, sociais, culturais ou políticos. E o livro didático é um recurso que deve auxiliar os alunos nessa compreensão, no sentido de aproximar o aluno dos conceitos geográficos que devem ser trabalhados em sala de aula, no sentido de ampliar as ideias sobre a vida, o espaço geográfico real, os lugares de vivencias e outros lugares que se articulam, nas mais variadas escalas de análise.

Pensar a forma como os livros abordam os conteúdos geográficos é importante por que o livro didático ainda é um elemento norteador na escolha dos conteúdos e da aula, pois de acordo com Frison (2009) tal instrumento atualmente torna-se um recurso básico para o aluno e o professor, no processo ensino-aprendizagem, em muitas escolas da rede pública de ensino básico, pois representa muitas vezes a principal, senão a única, fonte de trabalho com material impresso na sala de aula.

Um primeiro olhar sobre o conteúdo abordado nos livros didáticos, nos deu a impressão de que a abordagem do lugar é feita em segundo plano, a partir do desenvolvimento de outros assuntos abordados. A partir desse diagnostico inicial, para que fosse feita uma melhor analise sobre a abordagem desse conteúdo nos livros, alguns parâmetros foram traçados: 1) Número de páginas dedicadas ao estudo ou abordagem do Lugar; 2) Abordagem desse conceito na Apresentação; 3) Palavras-chave e conceitos abordados no livro para realização da análise; 4) Tratamento do conceito de lugar ao longo do livro; 5) Atividades propostas; 6) Articulação com o lugar de vivencia e com os conhecimentos dos alunos; 7) Exploração d o significado do lugar para os alunos. Ao iniciar a análise do tema Lugar nos livros didáticos (LD) investigados considerou-se, a princípio, as páginas destinadas a esse conteúdo, inclusive figuras, textos-boxes, exercícios e leitura complementar, sendo excluídos da contabilização o glossário, gabaritos e bibliografia.

O lugar pode ser entendido e analisado a partir da ideia de longitude e latitude relacionado no índice de um atlas; ou como um ponto de localização de lugares e / ou de fenômenos na superfície terrestre, isto é um ponto no mapa, conforme é tradicionalmente estudado na perspectiva da geografia denominada de positivista. Mas também pode ser estudado conforme o método da geografia crítico-marxista, como um ponto de articulação entre o local e o global, se constituindo como um laboratório para entender o mundo, uma vez que as ações que ocorrem no global repercutem-se em lugares específicos. Outra perspectiva para se estudar o lugar é decorrente da geografia humanista, onde o mesmo é entendido como um espaço que se torna familiar ao indivíduo, é o espaço do vivido, do experienciado, onde são considerados os sentimentos espaciais e as ideal de um grupo ou povo sobre o espaço a partir da experiência. Parte-se do pressuposto de que é no lugar onde atribuímos sentindo aos espaços, reconhecendo a legitimidade para localizar ações, expectativas, esperanças e 
possibilidades ali existentes. Compreender o lugar em que vive permite ao sujeito conhecer a história e conseguir entender as coisas que ali acontecem. Sobre isso, Cunha (2008, p 184) salienta que:

O lugar se constitui quando atribuímos sentido aos espaços, ou seja, reconhecemos a sua legitimidade para localizar ações, expectativas, esperanças e possibilidades. Quando se diz "esse é o lugar de", extrapolamos a condição de espaço e atribuímos um sentido cultural, subjetivo e muito próprio ao exercício de tal localização. Os lugares extrapolam uma base física e espacial para assumir uma condição cultural, humana, subjetiva e política. Entram em jogo as representações que os sujeitos fazem dos lugares e o sentido que atribuem aos mesmos.

Enquanto o conceito de lugar que trabalhamos e discutimos são de autores como Callai (2000, p.121) que diz que: "um lugar apresenta como uma das suas características a linearidade da ocupação - a sua horizontalidade - a expansão do uso do solo a partir de atividades especificas de cada lugar", nos livros didáticos trabalhados são mostrados o conceito de lugar misturados com o de espaço, território, urbano cidade e localização.

O momento no qual o conceito de lugar é apresentado articulando as relações sociais com o espaço de vivencia, é quando se é trabalhado a partir do conceito de urbano e cidade: no L1 traz que: O conceito de urbanização expressa o processo histórico de intensificação da vida nas cidades. Utiliza-se o termo urbano para designar as atividades e relações que se constroem ao seu redor que a caracteriza. O L2 diz que: o estudo de cidades tem como foco a análise do lugar e das vivencias cotidianas, ele contempla elementos da realidade próxima que afetam diretamente a vida as pessoas que nelas vivem e convivem.

As reflexões que se tem sobre esses espaços de vivencia é que a globalização se fez perder toda a singularidade existente em cada ambiente. É feita a historicização da constituição das cidades até chegar ao modelo que conhecemos atualmente. São trabalhados em duas escalas, a global e a brasileira. A conceituação de cidade no âmbito nacional é abordada de forma mais geral possível e apresentando de forma mais especifica as cidades da região do sudeste do Brasil como se a dinâmica existente nessas pudessem ser generalizadas para as outras regiões brasileiras, que tem tanta diversidade e peculiaridade de região para região, estado para estado, cidade para cidade e de bairro para bairro.

\section{CONSIDERAÇÕES FINAIS (ou Conclusão)}

Durante o período da pesquisa investigamos os conteúdos abordados e suas relações/adequações aos conceitos de lugar estudados no grupo de pesquisa e percebemos que o conceito lugar ocupa poucas páginas dos livros didáticos e que dessa forma o aluno não tem como compreender o que é lugar, para que isso aconteça e para compreenda o lugar no seu cotidiano dependerá da forma como esse conteúdo for apresentado e tratado em todo decorrer da disciplina pelo professor. Assim sendo identificamos que apesar do pouco conteúdo sobre lugar as atividades propostas nos livros didáticos com o conteúdo sobre lugar proporcionavam aos alunos reflexões sobre o seu espaço de vivência fazendo com que os alunos destingisse alguns ambientes e características particulares destes ambientes. Contudo acreditamos que todos os conteúdos, até mesmo os de outra disciplina, são melhores formados a partir da realidade e a experiência do aluno, para melhor compreender o global. Temos que ter ciência que os conteúdos, principalmente àqueles que se remetem os dados de determinados elementos que a Geografia. Nesse caso, o professor deve buscar 
informações em outras fontes, para complementar ou atualizar as informações do livro didático.

\section{REFERÊNCIAS}

HEMPE, Cléa. Lugar: Diferentes Significados. XVI Seminário Interinstitucional de Ensino, Pesquisa e Extensão. UNICRUZ. Outubro de 2011

FRISON, Marli Dallagnol; VIANNA, Jaqueline; CHAVES, Jéssica Mello; Bernardi, Fernanda Naimann. Livro Didático como Instrumento de Apoio para Construção de Propostas de Ensino de Ciências Naturais. VII Enepec. Florianópolis. 8 de novembro de 2009

SANTOS, Wildson Luiz; CARNEIRO, Maria Helena da Silva. Livro Didático de Ciências: Fonte de informação ou apostila de exercícios. In: Contexto e Educação: Ano 21. Julho/dezembro, Ijuí: Editora Unijuí. 2006.

THIESEN, Juares da Silva. Geografia escolar: dos conceitos essenciais às formas de Abordagem no ensino https://www.google.com.br/url?sa=t\&rct=j\&q=\&esrc=s\&source=web\&cd=1\&cad=rja\& uact $=8 \&$ ved=0ahUKEwiV3oDJ8cLSAhXDeSYKHSNZBeYQFggaMAA\&url=https\%3

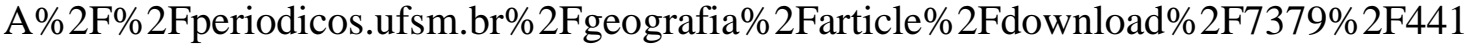
8\&usg=AFQjCNFFyraBO2dhsU7sFCn6q24Zi1Gg1g\&sig2=mrBUrD9CZS_clOMQZA oyXg\&bvm=bv.148747831,d.eWE acessado em 18/01/2017

VESENTINI, José William. A questão do livro didático no ensino da Geografia Novos caminhos da Geografia in Caminhos da Geografia. Ana Fani Alessandri Carlos(organizadora). 5.ed., $1^{\text {a }}$ reimpressão- São Paulo: Contexto,2007. 